An Assessment of High-Energy

Explosives and Metal Contamination

in Soil at TA-67 (12), L-Site, and

TA-14, Q-Site

Wallace Haywood

Dexter McRae

Jonathan Powell

Betty W. Harris 


\section{DISCLAIMER}

This report was prepared as an account of work sponsored by an agency of the United States Government. Neither the United States Government nor any agency thereof, nor any of their employees, make any warranty, express or implied, or assumes any legal liability or responsibility for the accuracy, completeness, or usefulness of any information, apparatus, product, or process disclosed, or represents that its use would not infringe privately owned rights. Reference herein to any specific commercial product, process, or service by trade name, trademark, manufacturer, or otherwise does not necessarily constitute or imply its endorsement, recommendation, or favoring by the United States Government or any agency thereof. The views and opinions of authors expressed herein do not necessarily state or reflect those of the United States Government or any agency thereof. 


\section{DISCLAIMER}

Portions of this document may be illegible in electronic image products. Images are produced from the best available original document. 


\section{CONTENTS}

ABSTRACT …

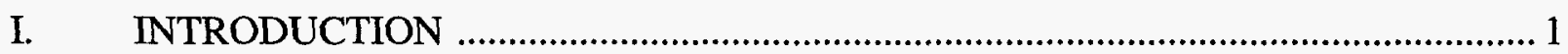

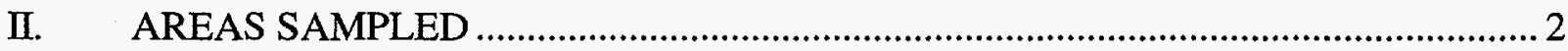

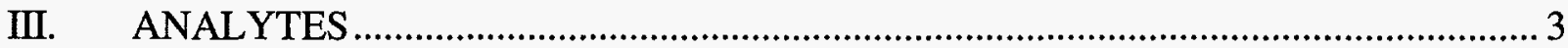

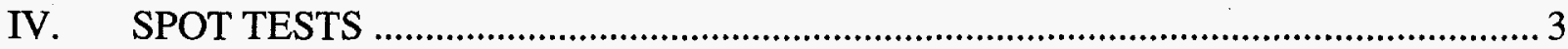

A. Old High-Energy Explosive (HE) Spot-Test Kit …………..................................... 3

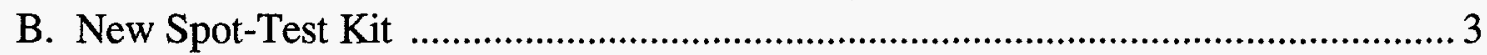

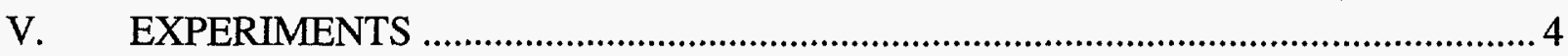

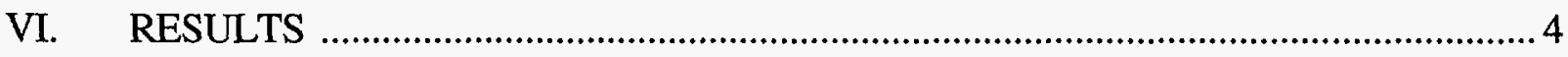

A. Hexagonal Closed Firing Pit ............................................................................... 4

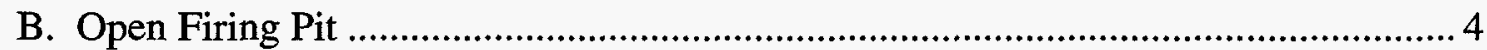

C. Firing Pad 1 Associated with Pull Box (Capacitor Discharge Unit) at TA-1 ........... 5

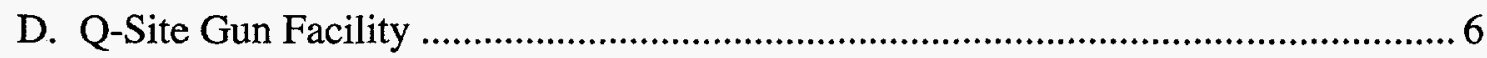

E. Q-Site Samples Previously Analyzed ……………..............................................

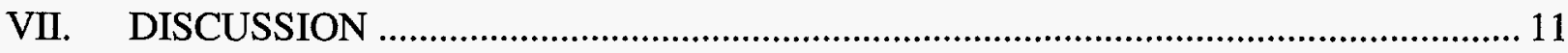

A. Tests for TNT and Related Compounds................................................................ 12

B. Tests for RDX, HMX, PETN, and Tetryl............................................................... 12

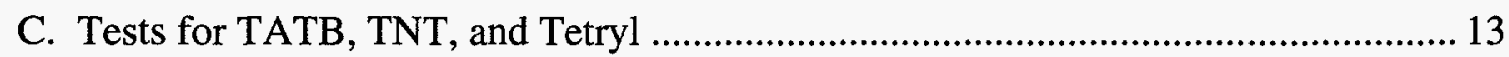

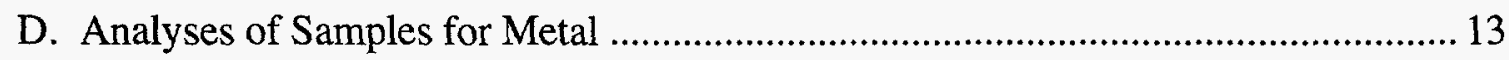

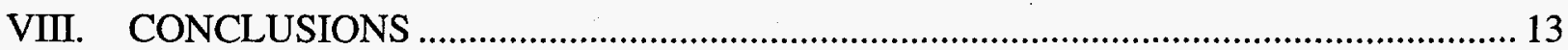

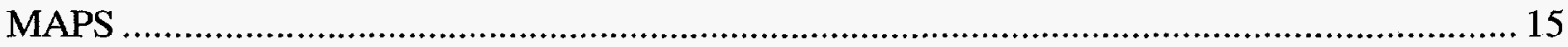

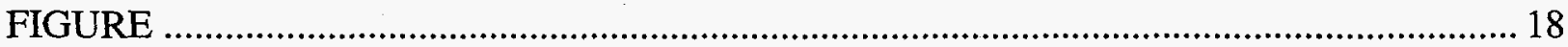




\title{
AN ASSESSMENT OF HIGH-ENERGY EXPLOSIVES \\ AND METAL CONTAMINATION IN SOIL AT \\ TA-67 (12), L-SITE, AND TA-14, Q-SITE
}

by

\section{Wallace Haywood, Dexter McRae, Jonathan Powell, and Betty W. Harris}

\begin{abstract}
The results of the field investigation to determine the kind and concentration of explosives found in the soil and on articles at sites known to be contaminated with energetic materials are given in this report. We are concerned about safety and health hazards associated with some explosives, nitro-organics and organic nitrates. Results from the use of the old and new field spot-test kits to detect the presence of energetic materials are given. Also included are data from the highperformance liquid chromatography (HPLC) analyses of acetonitrile extracts from $\mathrm{Q}$-Site soil samples, and data from the energy-dispersive $\mathrm{x}$-ray fluorescence (EDXRF) analyses for hazardous metals on the same samples.
\end{abstract}

\section{INTRODUCTION}

On the morning of June 24, 1993, a team of field investigators led by Calvin Martell visited TA67 (12), L-Site, located on Redondo Mesa (Map 1). The purpose of the visit was to establish the feasibility of using the field spot-test kits to detect explosives in soil samples in which there is known interference from other media. The field investigation team consisted of Calvin Martell (Group CST-1), Wallace Haywood (Group CST-4), Dexter McRae (Group CST-4), Peter Encinatis (Group ESA-3), Steve Watanabe (Group CST-DO), and Betty Harris (Group DX-16). Field tests were run by Dexter McRae, Wallace Haywood, and Betty Harris.

L-Site was constructed in the spring of 1945 and used for approximately one year as an explosives test facility, but it was abandoned in mid 1950. Inspection records of that decade indicate that several buildings, subsequently removed, were contaminated with explosives. In 1950 the Laboratory's Health Division used the eastern parameter of L-Site for radiation studies on animals and a section of the perimeter became contaminated with radiation. During the Vietnam War a portion of the site was used by a Laboratory group for "Mortar Locator" experiments in which an acetylene gas gun was part of the apparatus. There is a question about possible contaminants from this study. 


\section{AREAS SAMPLED}

The team sampled for unexploded energetic materials in the soil and on metal components around an inactive, closed firing pit, TA-12-4 (Map 1) and B-19 (Map 2). This pit is steel-lined, partially submerged, hexagonal, and 8-ft long per side by 12-ft deep. The pit was built in 1945 , after a similar one was abandoned at Far Point, and used for approximately one year as a containment vessel for the detonation of explosives and weapons components. It was decommissioned in 1953. TA-12-4 and the soil that surrounds it comprise Solid-Waste Management Unit 12-001a (SWMU 12-001a) in Operable Unit 1085. Also, we sampled for explosives in what is suspected as being the worst-case situation at L-Site, an inactive, open firing pit that lies about 200 yards due east of TA-12-4 on the north side of a utility road (Map 2). This open pit was used extensively in 1945, and on other occasions through 1953, to test weapons components containing uranium, possibly depleted uranium. The site is suspected of being contaminated with lead, uranium, and explosives. Visual evidence of yellow uranium oxide extends as far as eight feet from the pit on the east and north sides.

A few yards west of the open pit is an area with small chunks of formulated 1,3, 5-hexahydro-1, 3, 5-s-trinitro-triazine (royal demolition explosive, RDX) identified in the Group DX-16 laboratory of Terry Spontarelli. The hard, rock-like pink pieces of explosives are scattered in a graveled semicircle that has two trees at the outer south edge. Also collected was one piece of yellowish brown material believed to be both RDX and octahydro-1,3,5,7-tetranitro-1,3,5,7tetraazocine (high-melting explosive, $\mathrm{HMX}$ ) and possibly some other compound and a binder. This contamination, scattered chunks of explosives, may have resulted from a partial detonation in an attempt to dispose of explosives found in the area during the 1970 s.

To ensure that we had test results from an area that is known to be contaminated, we sampled an active open firing mound at TA-14, Q-Site (Map A). Q-Site has been used for development and testing of explosives since 1944. Swipes were taken from the first firing pad near the Control Room, TA-14-23, the back side of the retainer wall associated with this pad, and the surrounding soil about three feet from the firing pad.

In the afternoon of June 25, 1993, Dexter McRae, Wallace Haywood, and Betty Harris also sampled the soil and metal components in and around the Gun Facility located at the west end of TA-14, Q-Site (Map B). 
Dried soil samples and articles from Q-Site, taken on a prior visit, were also tested using the spot-test kits. These samples had been analyzed by high-performance liquid chromatography (HPLC) for explosives and the hazardous metal concentrations were determined by energydispersive $\mathrm{x}$-ray fluorescence (EDXRF).

\section{ANALYTES}

We tested for 1,3,5-trinitrotoluene (TNT), RDX, HMX, pentaerythritoltetranitrate (PETN), 1,3,5-trinitrophenylmethylnitramine (tetryl), 1,3,5-triamono-2,4,6-trinitrobenzene (TATB), and 1,3,5-trinitrophenol (picric acid), see Fig. 1.

\section{SPOT TESTS}

\section{A. Old High-Energy Explosive (HE) Spot-Test Kit}

The old HE spot-test kit consists of three reagents known as

- Reagent A [an 80\%/20\% mixture of the solvent, N,N-dimethylformamide (DMF) and di$\mathrm{N}$-butylamine], used to test for TNT and explosives that are similar in structure (aromatic amines);

- Reagent B [tetra-N-butylammonium hydroxide in methanol with a fluorescence dye dissolved in dimethyl sulfoxide (DMSO), 2\%/98\%, as an indicator], used to test for RDX, HMX, and PETN (once applied, the solution is viewed under an ultraviolet light to enhance the color of this test); and

- Reagent C [potassium hydroxide, water, DMSO, 5/5/90 wt\%], used to test for TATB, which gives a distinct orange color when applied to a contaminated area. It also gives a color distinctly different than the color for TATB when other explosives are present: a red color for tris-picrylamino-1,3,5-triazine (PYX), hexanitrostilbene (HNS), and tetryl, and a purple to black color for TNT.

\section{B. New Spot-Test Kit}

The new field spot-test kit consists of

- Reagent $C$ from the old kit, more concentrated, now called Solution 1;

- Hydrochloric acid and sulfanilide, Solution 2; and

- N-naphthalenediamine dihydrochloride, Solution 3. 


\section{EXPERIMENTS}

While in the field, we swiped soil and metal surfaces of the closed firing pit (TA-12-4), the RDX visibly contaminated soil of a semicircle, and the soil in an open firing pit. The latter two are located due east and near TA-12-4. We used both old and new field spot-test kits. We also sampled scoops of soil from these areas by putting the soil on the filter paper and adding the test reagent or solution. Samples weighing about $10 \mathrm{~g}$ each were taken back to the laboratory from each location and tested with all of the reagents from both spot-test kits.

Reagent A and Reagent C (Solution 1) were used first to test the soil samples. Then all three solutions from the new kit were tried. Note that Reagent $B$ from the old kit, used to test for PETN, RDX, and HMX, was not used in the field but was used to test for explosives in all samples in the laboratory.

\section{RESULTS}

\section{A. Hexagonal Closed Firing Pit}

The outer walls of the closed firing pit at TA-12-4 (SWMU-12-001a) were swiped and the results were negative. Metal pieces on the ground near the opening of the pit were tested; all were negative. Surface swipes of the soil around the pit were tested; all results were negative.

On June 14, 1993, Ken Uher (Group DX-16) was lowered into the pit. He took samples of the white residue on the walls, swipes from the inside walls, and soil from the bottom of the pit. All samples tested negative for explosives.

\section{B. Open Firing Pit}

All swipes of the soil surface and scoops of soil analyzed in the field at TA-67(12) were negative. The material, believed to be uranium oxide, also tested negative for explosives. The very hard, formulated, pink pieces of material found scattered in a semicircle east of the closed firing pit and very near two trees tested positive for RDX. When grains from these pieces were put into the soil, the soil tested positive. This material had been analyzed previously by Terry Spontarelli (Group DX-16) and shown to be RDX and a plastic binder. The results of the laboratory tests of soil samples are given in Table $\mathrm{I}$. 
TABLE I. The results of field spot tests for explosives on samples taken from surface swipes and scoops of soil taken at L-Site [the closed pit (TA-12-4), the open pit, and a semicircular area $25 \mathrm{ft}$ west of the open pit].

\begin{tabular}{|c|c|c|c|c|}
\hline Location & Sample Number/ID & Reagent A & Reagent C & All Reagents \\
\hline Open Pit (Center) & 1 & $\mathrm{NR}^{1}$ & $\mathrm{NR}$ & NR \\
\hline Open Pit (Center) & 2 & NR & $\mathrm{NE}$ & NR \\
\hline Open Pit (Center) & 3 & NR & NR & NR \\
\hline Open Pit (Center) & 4 & NR & NR & NR \\
\hline Open Pit (Center) & 5 & NR & NR & NR \\
\hline South Tree & Edge & NR & NR & NR \\
\hline $25 \mathrm{ft} \mathrm{W}$ of Open Pit & Pieces of Pink HE & NR & ? & $\mathrm{R}^{2}$ \\
\hline $25 \mathrm{ft} \mathrm{W}$ of Open Pit & Soil Composite & NR & NR & NR \\
\hline $25 \mathrm{ft} \mathrm{W}$ of Open Pit & Center of Area & NR & NR & NR \\
\hline $25 \mathrm{ft} \mathrm{W}$ of Open Pit & Ridge By Trench & NR & NR & NR \\
\hline $25 \mathrm{ft} \mathrm{W}$ of Open Pit & Rim Composite & NR & NR & NR \\
\hline Open Pit & HE pieces & NR & NR & $\mathbf{R}$ \\
\hline Open Pit, $5 \mathrm{ft}$ NW & $\begin{array}{l}\text { Small Yellowish } \\
\text { Brown Pieces of } \mathrm{HE}^{3}\end{array}$ & Purple & Purple & Purple \\
\hline Closed Pit & Soil & NR & NR & NR \\
\hline Open Pit, $8 \mathrm{ftE}$ of Tree & Uranium Oxide & NR & NR & NR \\
\hline \multicolumn{5}{|c|}{$\begin{array}{l}1 \mathrm{NR}=\text { No Reaction } \\
2 \mathrm{R}=\text { Reaction } \\
{ }^{3} \text { Gave a Deep Purple Color With Reagent } \mathrm{B}\end{array}$} \\
\hline
\end{tabular}

\section{Firing Pad 1 Associated with Pull Box (Capacitor Discharge Unit) at TA-1}

Three swipes were taken from the first firing pad near the control room (Map A); all were negative. A yellow material embedded in the center panel of the retaining wall of the firing pad tested positive for TNT. Swipes of the center wall were negative for TNT. Scoops of soil taken from a circle approximately $3 \mathrm{ft}$ in diameter that encompassed the firing pad tested positive for TNT. The color was very faint which indicated a very low concentration of explosive in the sandy soil sample that covered the firing mound. During cleanup of this area, fresh sand is routinely brought in to provide a new covering over the mounds where firing operations are done. Table II shows the results of the field spot-test kit for explosives on other samples taken at Q-Site. 
TABLE II. Q-Site samples taken prevously from firing mounds and surrounding areas for HPLC analyses of eight basic explosives, TNT impurities, and degradation products.

\begin{tabular}{|c|c|c|c|c|c|}
\hline Location & Sample Number & Reagent A & Reagent B & Reagent C & All Solutions \\
\hline Firing Pad 1 & 1 & $\mathrm{R}^{4}$ & $N T^{5}$ & $\mathrm{R}$ & $\mathrm{R}$ \\
\hline Firing Pad 1 & 2 & $\mathrm{R}$ & NT & $\mathbf{R}$ & $\mathbf{R}$ \\
\hline Firing Pad 1 & 3 & $N^{6}$ & NT & NR & $\mathbf{R}$ \\
\hline Firing Pad 1 & 4 & NR & NT & NR & $\mathbf{R}$ \\
\hline Firing Pad 1 & 5 & NR & NT & NR & $\mathrm{R}$ \\
\hline Firing Pad 2 & 1 & NR & NT & NR & $\mathbf{R}$ \\
\hline Firing Pad 2 & 2 & NR & NT & NR & $\mathbf{R}$ \\
\hline Firing Pad 3 & 1 & NR & NT & NR & NR \\
\hline Firing Pad 3 & 2 & NR & NT & NR & NR \\
\hline Firing Pad 3 & 3 & NR & NT & NR & $\mathbf{R}$ \\
\hline Q-Site West & $\begin{array}{l}\text { Underground } \\
\text { Cable }\end{array}$ & NR & NT & NR & NR \\
\hline $\begin{array}{l}\text { Fire Hydrant } \\
\text { Near Entrance } \\
\text { W Side }\end{array}$ & Soil & NR & NT & NR & NR \\
\hline \multicolumn{6}{|c|}{$\begin{array}{l}{ }^{4} \mathrm{R}=\text { Reaction } \\
{ }^{5} \mathrm{NT}=\text { Not Tested } \\
{ }^{6} \mathrm{NR}=\text { Negative Results }\end{array}$} \\
\hline
\end{tabular}

The samples in Table III, Firing Pad 3, were also analyzed for picric acid. The concentration was less than $0.2 \mathrm{mg} / \mathrm{kg}$. The area became contaminated with picric acid when a shot designed to dispose of waste explosives failed to detonate.

\section{Q-Site Gun Facility}

We tested the firing pedestal, TA-14-44, of the Gun Facility located at the west end of Q-Site (Map B). The pedestal held a large barrel-shaped containment vessel. Swipes were taken from the metal component and scoops of soil were tested. We obtained several questionable positive tests that were not very intense, which caused us to worry about false positive. Results from these tests are given in Table IV. 
TABLE III. HPLC analyses of the solution from the extraction of Q-Site soil with acetonitrile. [Samples were analyzed using a UV detector at $254 \mathrm{~nm}$.]

\begin{tabular}{|c|c|c|c|}
\hline $\begin{array}{l}\text { Location } \\
\text { Firing Pad }\end{array}$ & $\begin{array}{c}\text { Sample } \\
\text { Number/ID }\end{array}$ & Compound & Concentration $\mu \mathrm{g} / \mathrm{g}$ \\
\hline 1 & 1 & HMX & 82.7 \\
\hline 1 & 1 & $\mathrm{RDX}$ & 4.2 \\
\hline 1 & 1 & Tetryl & $<0.4$ \\
\hline 1 & 1 & TNT & 15.8 \\
\hline 1 & 1 & 2,4-DNT & $<0.2$ \\
\hline 1 & 2 & HMX & 174.5 \\
\hline 1 & 2 & $\mathrm{RDX}$ & 2.6 \\
\hline 1 & 2 & Tetryl & $<0.4$ \\
\hline 1 & 1 & TNT & 0.8 \\
\hline 1 & 1 & 2,4-DNT & $<0.2$ \\
\hline 1 & 3 & HMX & 215.0 \\
\hline 1 & 3 & $\mathrm{RDX}$ & 3.2 \\
\hline 1 & 3 & Tetryl & $<0.4$ \\
\hline 1 & 3 & TNT & 0.8 \\
\hline 1 & 2 & 2,4-DNT & $<0.2$ \\
\hline 1 & 4 & HMX & 168.6 \\
\hline 1 & 4 & RDX & 3.4 \\
\hline 1 & 4 & Tetryl & $<0.4$ \\
\hline 1 & 4 & TNT & 1.0 \\
\hline 1 & 4 & $2,4 \mathrm{DNT}$ & $<0.2$ \\
\hline 1 & 5 & HMX & 315.0 \\
\hline 1 & 5 & $\mathrm{RDX}$ & 1.8 \\
\hline 1 & 5 & Tetryl & $<0.4$ \\
\hline 1 & 5 & TNT & 0.6 \\
\hline 1 & 5 & 2,4-DNT & $<0.2$ \\
\hline 1 & & HMX & 72.8 \\
\hline 1 & 6 & RDX & 6.0 \\
\hline 1 & 6 & Tetryl & $<0.4$ \\
\hline 1 & 6 & TNT & 0.6 \\
\hline 1 & 6 & $2,4-\mathrm{DNT}$ & $<0.2$ \\
\hline 1 & 7 & $\mathrm{HMX}$ & 111.3 \\
\hline 1 & 7 & RDX & 6.0 \\
\hline 1 & 7 & Tetryl & $<0.4$ \\
\hline 1 & 7 & TNT & 1.4 \\
\hline 1 & 7 & 2,4-DNT & $<0.2$ \\
\hline $5 \mathrm{~N} 2$ & 8 & $\mathrm{HMX}$ & 186.0 \\
\hline $5 \mathrm{~N} 2$ & 8 & RDX & 0.4 \\
\hline $5 \mathrm{~N} 2$ & 8 & Tetryl & $<0.4$ \\
\hline $5 \mathrm{~N} 2$ & 8 & TNT & 0.4 \\
\hline $5 \mathrm{~N} 2$ & 8 & 2,4-DNT & $<0.2$ \\
\hline
\end{tabular}




\begin{tabular}{|c|c|c|c|}
\hline \multicolumn{4}{|c|}{ TABLE III. (Continued) } \\
\hline $\begin{array}{l}\text { Location } \\
\text { Firing Pad }\end{array}$ & $\begin{array}{c}\text { Sample } \\
\text { Number/ID }\end{array}$ & Compound & Concentration $\mu \mathrm{g} / \mathrm{g}$ \\
\hline 2 & 9 & $\mathrm{HMX}$ & 39.8 \\
\hline 2 & 9 & RDX & 1.6 \\
\hline 2 & 9 & Tetryl & $<0.4$ \\
\hline 2 & 9 & TNT & 0.8 \\
\hline 2 & 9 & 2,4-DNT & $<0.2$ \\
\hline 3 & 1 & HMX & 6.8 \\
\hline 3 & 1 & RDX & 10.0 \\
\hline 3 & 1 & Tetryl & $<0.4$ \\
\hline 3 & 1 & TNT & $<0.4$ \\
\hline 3 & 1 & $2,4-\mathrm{DNT}$ & $<0.2$ \\
\hline 3 & 2 & HMX & 11.8 \\
\hline 3 & 2 & RDX & $<0.3$ \\
\hline 3 & 2 & Tetryl & $<0.4$ \\
\hline 3 & 2 & TNT & $<0.4$ \\
\hline 3 & 2 & 2,4-DNT & $<0.2$ \\
\hline 3 & 3 & HMX & 9.3 \\
\hline 3 & 3 & RDX & 1.2 \\
\hline 3 & 3 & Tetryl & $<0.4$ \\
\hline 3 & 3 & TNT & $<0.4$ \\
\hline 3 & 3 & 2,4-DNT & $<0.4$ \\
\hline 3 & 4 & HMX & 11.8 \\
\hline 3 & 4 & $\mathrm{RDX}$ & $<0.3$ \\
\hline 3 & 4 & Tetryl & $<0.4$ \\
\hline 3 & 4 & TNT & $<0.4$ \\
\hline 3 & 4 & 2,4-DNT & $<0.2$ \\
\hline 3 & 5 & HMX & 2.4 \\
\hline 3 & 5 & RDX & $<0.3$ \\
\hline 3 & 5 & Tetryl & $<0.4$ \\
\hline 3 & 5 & TNT & $<0.4$ \\
\hline 3 & 5 & 2,4-DNT & $<0.2$ \\
\hline West Side & Electric Cable & HMX & 0.6 \\
\hline West Side & Electric Cable & RDX & $<0.3$ \\
\hline West Side & Electric Cable & Tetryl & $<0.4$ \\
\hline West Side & Electric Cable & TNT & $<0.4$ \\
\hline West Side & Electric Cable & 2,4-DNT & $<0.2$ \\
\hline East Gate & Fire Hydrant & HMX & $<0.3$ \\
\hline East Gate & Fire Hydrant & $\mathrm{RDX}$ & $<0.3$ \\
\hline East Gate & Fire Hydrant & Tetryl & $<0.4$ \\
\hline East Gate & Fire Hydrant & TNT & $<0.4$ \\
\hline East Gate & Fire Hydrant & 2,4-DNT & $<0.2$ \\
\hline
\end{tabular}


TABLE IV. Analyses of samples from the Q-Site West firing pedestal at the Gun Facility. [Samples were taken from a metal barrel-shaped containment vessel, soil in this vessel, and sand near the target stand.]

\begin{tabular}{lcccc}
\hline Sample & Reagent A & Reagent B & Reagent C & All Solutions \\
\hline Target Table & $\mathrm{NR}$ & $?^{8}$ & $\mathrm{NR}$ & $\mathrm{R}^{9}$ \\
Barrel Material (Yellow) & $\mathrm{NR}$ & $?$ & $\mathrm{NR}$ & $\mathrm{R}$ \\
Barrel (West End) & $\mathrm{NR}$ & $(\mathrm{R}) ?$ & $\mathrm{NR}$ & $\mathrm{R}$ \\
Metal Plate (In Barrel) & $\mathrm{NR}$ & $\mathrm{NR}$ & $\mathrm{NR}$ & $\mathrm{NR}$ \\
Barrel (Center) & $\mathrm{NR}$ & $\mathrm{NR}$ & $\mathrm{NR}$ & $\mathrm{R}$ \\
Target Plate & $\mathrm{NR}$ & $\mathrm{R}) ?$ & $\mathrm{NR}$ & $\mathrm{R}$ \\
Black Soil (East End) & $\mathrm{NR}$ & $\mathrm{Green}$ & $\mathrm{R}$ & $\mathrm{R}$ \\
Barrel (Oily Black Soil) & $\mathrm{NR}$ & $\mathrm{R}) ?$ & $\mathrm{R}$ & $\mathrm{R}$ \\
Barrel (Clean Soil) & $\mathrm{NR}$ & $\mathrm{NR}$ & $\mathrm{R}$ & $\mathrm{R}$ \\
Barrel (Right Side) & $\mathrm{NR}$ & $\mathrm{R}$ & $\mathrm{R}$ & $\mathrm{R}$ \\
\hline${ }^{7} \mathrm{NR}=$ No Reaction & & & & \\
8 ? Color different than expected & & & \\
${ }^{9} \mathrm{R}=$ Reaction & & & & \\
\hline \hline
\end{tabular}

\section{E. Q-Site Samples Previously Analyzed}

About fifteen samples had been taken previously from Q-Site and analyzed with HPLC for the basic explosives, impurities, and decomposition products. We included these samples in our spot-test analyses and the results are given in Table II. The concentrations of the various explosives, HMX, RDX, tetryl, TNT, and 2,4-DNT, are given in Table III. HMX was the most concentrated of all of the explosives in the soil (sand) with concentrations ranging from a few tenths of a ppm to over $300 \mathrm{ppm}$. Firing Mound 1 was the most contaminated.

Also, we analyzed several samples for metals using EDXRF. The concentrations of metals and the screening-action levels (SALs) are given in Table V. SALs are concentrations of materials that, if exceeded, will require a hazard assessment to be done. Values for the most concentrated of the toxic metals, chromium, mercury, and lead, are shown to be less than SALs. Therefore they would not pose a health hazard to workers. One sample, number 7, exceeded the SAL for uranium and should be treated as a health hazard to workers. 
TABLE V. Metal concentrations in ppm for samples taken from Firing Mounds 1, 2, 3 and the burn pit at TA-14, Q-Site. ${ }^{\text {[ }}$ [Analyses were performed by EDXRF.]

\begin{tabular}{|c|c|c|c|c|}
\hline \multirow[b]{2}{*}{$\begin{array}{l}\text { Sample } \\
\text { Number }\end{array}$} & \multicolumn{4}{|c|}{ Elements and SALs (ppm) } \\
\hline & Chromium (400) & Mercury (24) & Lead (500) & Uranium (240) \\
\hline 2 & 208.2 & 0.4 & 27.0 & 3.7 \\
\hline 3 & 33.8 & 0.5 & 32.1 & 4.1 \\
\hline 4 & $\mathrm{ND}^{10}$ & 1.2 & 15.4 & 21.63 \\
\hline 5 & ND & ND & 67.6 & 3.1 \\
\hline 6 & ND & 0.7 & 13.9 & 19.9 \\
\hline 7 & 76.2 & 0.5 & 24.0 & 648.0 \\
\hline 8 & ND & 0.3 & 78.8 & 16.2 \\
\hline 9 & 51.9 & 5.0 & 44.06 & 6.7 \\
\hline 10 & 195.2 & ND & 3.9 & 3.3 \\
\hline 11 & 58.4 & 0.1 & 46.7 & 32.7 \\
\hline 12 & ND & ND & ND & 16.1 \\
\hline 13 & 79.8 & 1.3 & 38.4 & 24.3 \\
\hline 14 & 97.8 & ND & 15.3 & 6.4 \\
\hline 15 & 2.8 & 0.9 & 13.8 & ND \\
\hline 16 & $\mathrm{ND}$ & ND & 24.5 & 21.2 \\
\hline 17 & 287.6 & 2.0 & 38.7 & 8.0 \\
\hline 18 & 132.4 & 0.9 & ND & 14.8 \\
\hline 19 & ND & 0.8 & ND & ND \\
\hline 20 & ND & ND & ND & 19.2 \\
\hline 21 & ND & ND & 45.1 & ND \\
\hline 22 & ND & ND & ND & 20.7 \\
\hline $\begin{array}{l}\text { thoug } \\
D=N\end{array}$ & $\begin{array}{l}\text { ed samples ar } \\
\text { ted }\end{array}$ & d, a profile & and an & \\
\hline
\end{tabular}

The $\mathrm{pH}$ of the soil is also given. This is an important piece of data because its helps determine whether or not the metals are bound or migrating in the soil. Several of the metals are mobile in most acidic soils. The $\mathrm{pH}$ values for Q-Site soils are shown in Table VI. The $\mathrm{pH}$ of the soil is slightly acidic to slightly basic at Firing Mounds 1 and 2 and parts of Firing Mound 3. However, other areas were very acidic as indicated by samples from Firing Mound 3 (see Table VII), a sample from near an electrical cable at the west end of Q-Site, and a sample from the area of the fire hydrant at the entrance gate for TA-14. 
TABLE VI. The $\mathrm{pH}$ of Q-Site soil samples.

\begin{tabular}{ccc}
\hline Location Firing Pad & Sample & pH \\
\hline 1 & 1 & 6.85 \\
1 & 2 & 6.80 \\
1 & 3 & 7.06 \\
1 & 4 & 7.27 \\
1 & 5 & 6.86 \\
1 & 6 & 7.38 \\
1 & 7 & 7.43 \\
2 & 8 & 7.34 \\
2 & 9 & 6.81 \\
3 & $10(1)$ & 6.26 \\
3 & $11(3)$ & 4.27 \\
3 & $12(4)$ & 5.50 \\
3 & $13(5)$ & 7.40 \\
West Side & Electric Cable & 4.91 \\
East Gate & Fire Hydrant & 4.76 \\
\hline \hline
\end{tabular}

TABLE VII. Analyses of TA-14, Q-Site, soil from Firing Mound 3 for picric acid after removal of top soil.

\begin{tabular}{cclc}
\hline Location Firing Pad & SampleNumber & Compound & Concentration $\mu \mathrm{g} / \mathrm{g}$ \\
\hline 1 & 3 & Picric Acid & $<0.2$ \\
3 & 1 & Picric Acid & $<0.2$ \\
3 & 3 & Picric Acid & $<0.2$ \\
3 & 4 & Picric Acid & $<0.2$ \\
3 & 5 & Picric Acid & $<0.2$ \\
\hline \hline
\end{tabular}

\section{DISCUSSION}

The chemistry of the field spot-test kit for explosives has been well established since the 19th century. The application of this chemistry to soils is being explored by several laboratories. Thomas F. Jenkins and Marianne E. Walsh (U.S. Army Cold Regions Research and Engineering Laboratory, Hanover, New Hampshire) have made significant progress in quantifying a kit similar to ours for field studies. Our kit needs to be tested against the by-products and results from soils that have been tested. 


\section{A. Tests for TNT and Related Compounds}

TNT was not found in any of the soil samples tested at TA-67 (12), yet it was the explosive used most frequently during World War II. TNT is believed to biodegrade rapidly in nature after an undetermined length of time and, therefore, is not detected by the spot tests used. However, the brown pieces of material with bead-like crystals on their surfaces did test positive for TNT (see Table I). This material was not sensitive to a hammer blow.

At Q-Site East, a positive test for TNT resulted from the solid taken from the containment wall at Mound 1 and the surrounding soil that was scooped up but not from the soil that was swiped nor the swipe from the metal firing pad. Nearly all of the Q-Site samples shown in Table II gave negative test results for TNT, although the HPLC analyses showed ppm concentration levels of this compound. Soil and metal objects at the Q-Site West Gun Facility tested negative for TNT.

\section{B. Tests for RDX, HMX, PETN, and Tetryl}

Tests for the other explosives (RDX, HMX, PETN, TATB, and tetryl) in the soil at L-Site and in the metal part of the hexagonal closed firing pit, TA-12-4, at L-site were also negative.

Negative tests were obtained for soils from the open firing pit, except for cases in which small pieces of suspected explosives from the ground were placed in the sample to be tested. This suspected explosive was very hard, plastic-like material scattered four to eight feet from the open pit. This material was sensitive to a hammer blow.

RDX was found in chunks at TA-12 but did not give a positive test with the spot test kit. Solubility was a factor in these results. The presence of RDX was expected in both the cast explosives used during the 1940s and the present-day Plastic Bonded Explosives (PBXs) used by DX- and ESA-Divisions.

Tests for explosives in the soil and swipes of objects were found to be positive for all active areas of TA-14, Q-Site. Reagents A and C of the old kit and Solution 1 from the new kit all confirmed the presence of TNT. All three solutions from the new kit were used to confirm the presence of RDX, HMX, and PETN or compounds that, when hydrolyzed, produce $\mathrm{NO}_{2}$ ions. At Q-Site West, we questioned the results from all three solutions of the new spot-test kit. The deep purple blue color, though obviously present, was very faint and in some cases was slow to develop. When Reagent B from the old kit was used in the Q-Site West soils, a greenish color different than the deep purple blue expected was produced. Interference from another contaminant or the $\mathrm{pH}$ of the soil could have an effect on this test. All three test solutions from the new spot-test kit seem to be better indicators for HMX. From HPLC analyses, HMX remains in the Q-Site soil 
and at higher concentrations than the other explosives. HMX may have been used more frequently and/or the half-life of the HMX in the Q-Site soil may be longer than that of other explosives.

\section{Tests for TATB, TNT, and Tetryl}

Reagent $\mathrm{C}$ and Solution 1 (identical except in concentration) were also used to confirm the presence of TATB (orange color), TNT (purple color), and tetryl (red color). Neither TATB nor tetryl were found in the swipe tests of soils at Q-Site. At L-Site, TATB was not used in explosive tests; therefore, its absence is not surprising.

\section{Analyses of Samples for Metal}

The EDXRF analyses for metals revealed no significant metal contamination, although detectable levels of some hazardous metals were found, and in one sample uranium exceeded the SAL of 240 ppm (see Table V). Depleted uranium is the form used in most tests.

\section{CONCLUSIONS}

The spot-test kits could not be reliably used to swipe soils and could not confirm, with confidence, the presence or absence of explosives for some of the sites tested. We obtained negative results, even though we had experimental evidence that the soil in one area was contaminated. This was true for the open firing pit at L-Site where scattered explosives could be picked up but contamination was not detected with either spot-test kit. If the concentration of explosive is above a certain level, then one can test scoops of soil and increase the probability of obtaining positive results, as was done at Q-Site. There is a need to quantify the detection concentration limits on these tests.

Both L- and Q-Sites are sandy loam and the firing mound at the latter is sand. Given the very low solubility of explosives in this soil and the nearly fifty years of weathering, especially at L-Site, the probability of swiping the exact location where a grain of explosive is found is very low. Even the soil beneath the chunks of formulated explosives at L-Site gave negative results. It is a matter both of explosive concentration and locating a contaminated area. The concentration of explosives dissolved in the soil at L-Site is extremely low, whereas ppm levels of explosives were found in the Q-Site soil. 
From this data, we would not recommend the use of the spot-test kits, without other determining methods, to screen for explosive contamination in the soil. This is true where firing operations have been conducted and explosives scattered.

Of the several metals analyzed, chromium, mercury, lead, and uranium, only uranium exceeded SALs. 


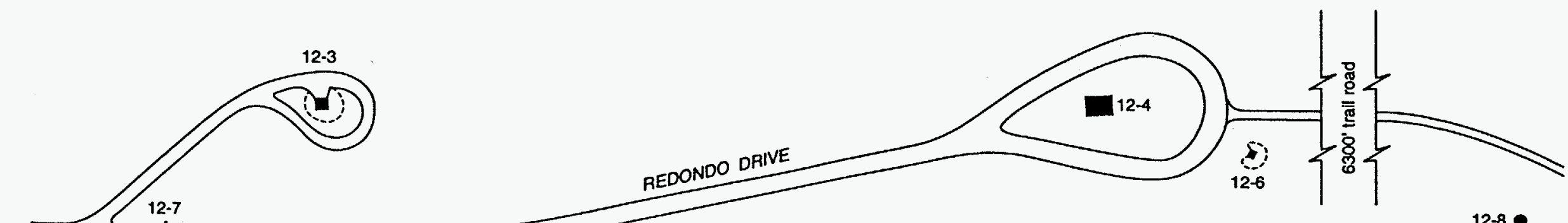

$12-8$

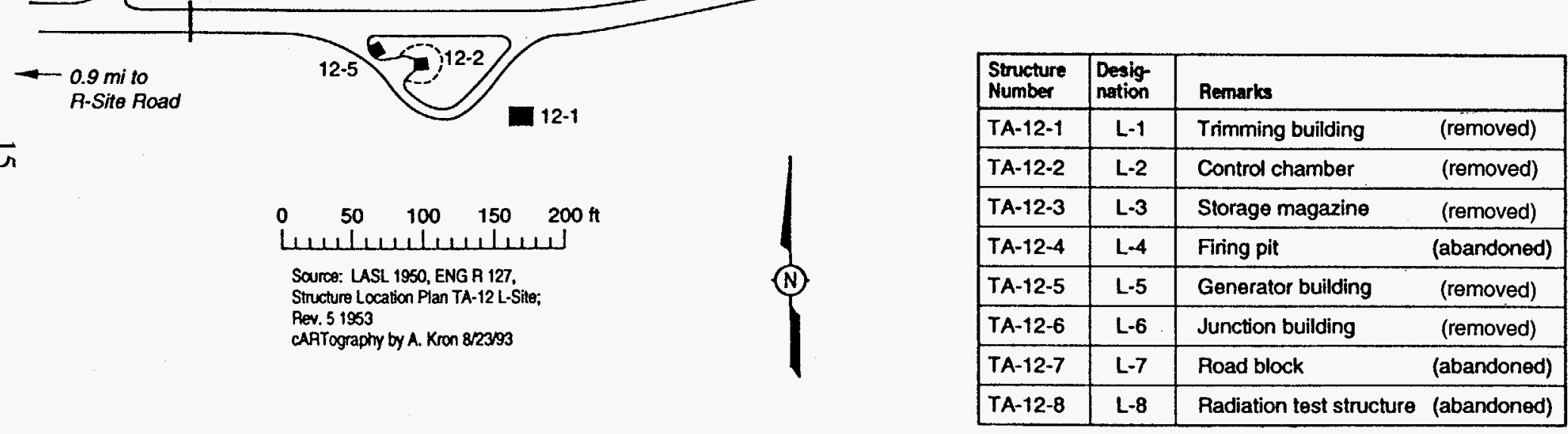

(Structure sites at TA-67, formerly TA-12, are still known by their original designations.)

Map 1 - TA-67 (12) L-Site 


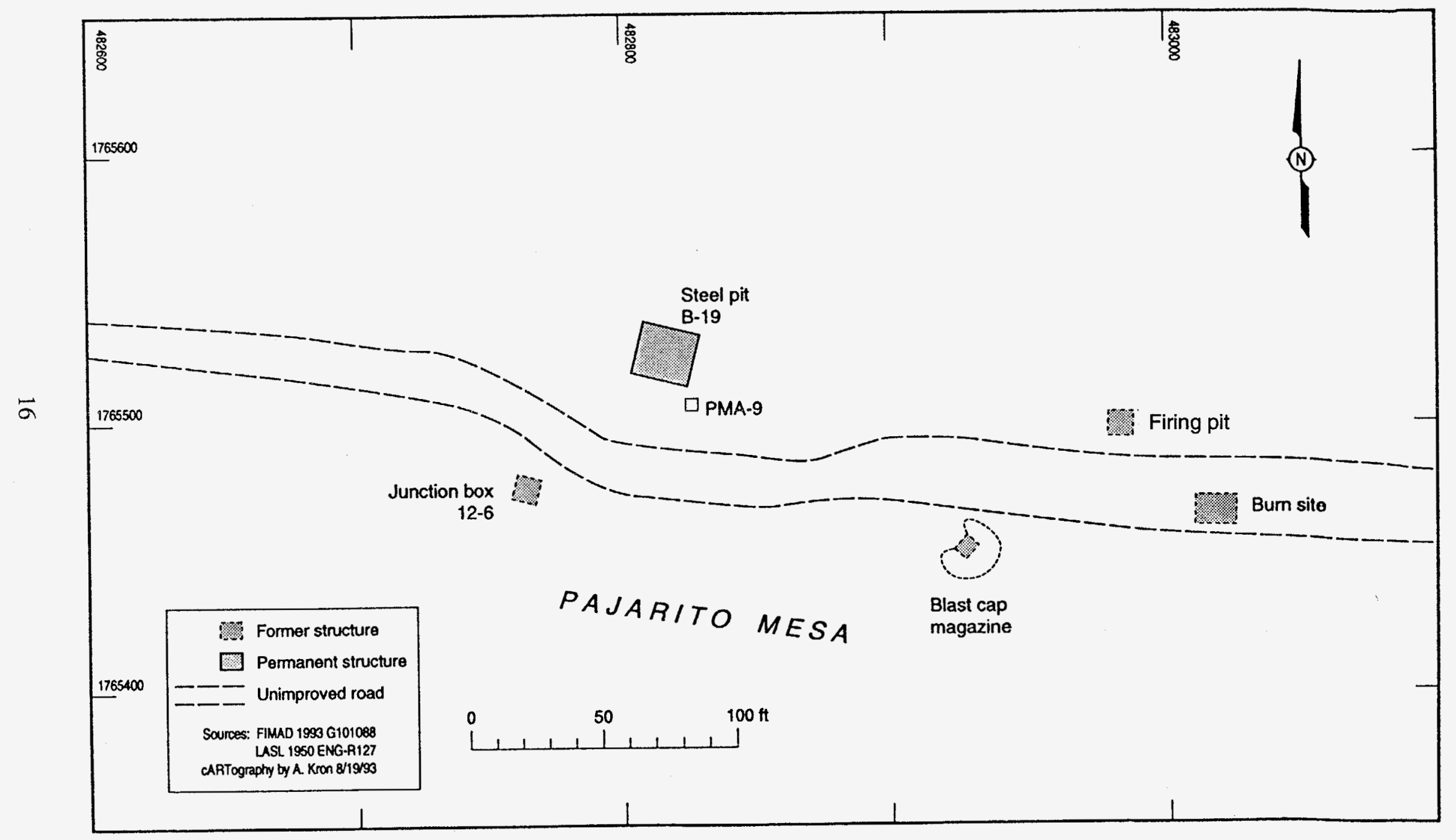

Map 2 - TA-67(12), L-Site with Steel Hexagonal Enclosed Firing Pit, B-19, Open Firing Pit, and Burn Site 

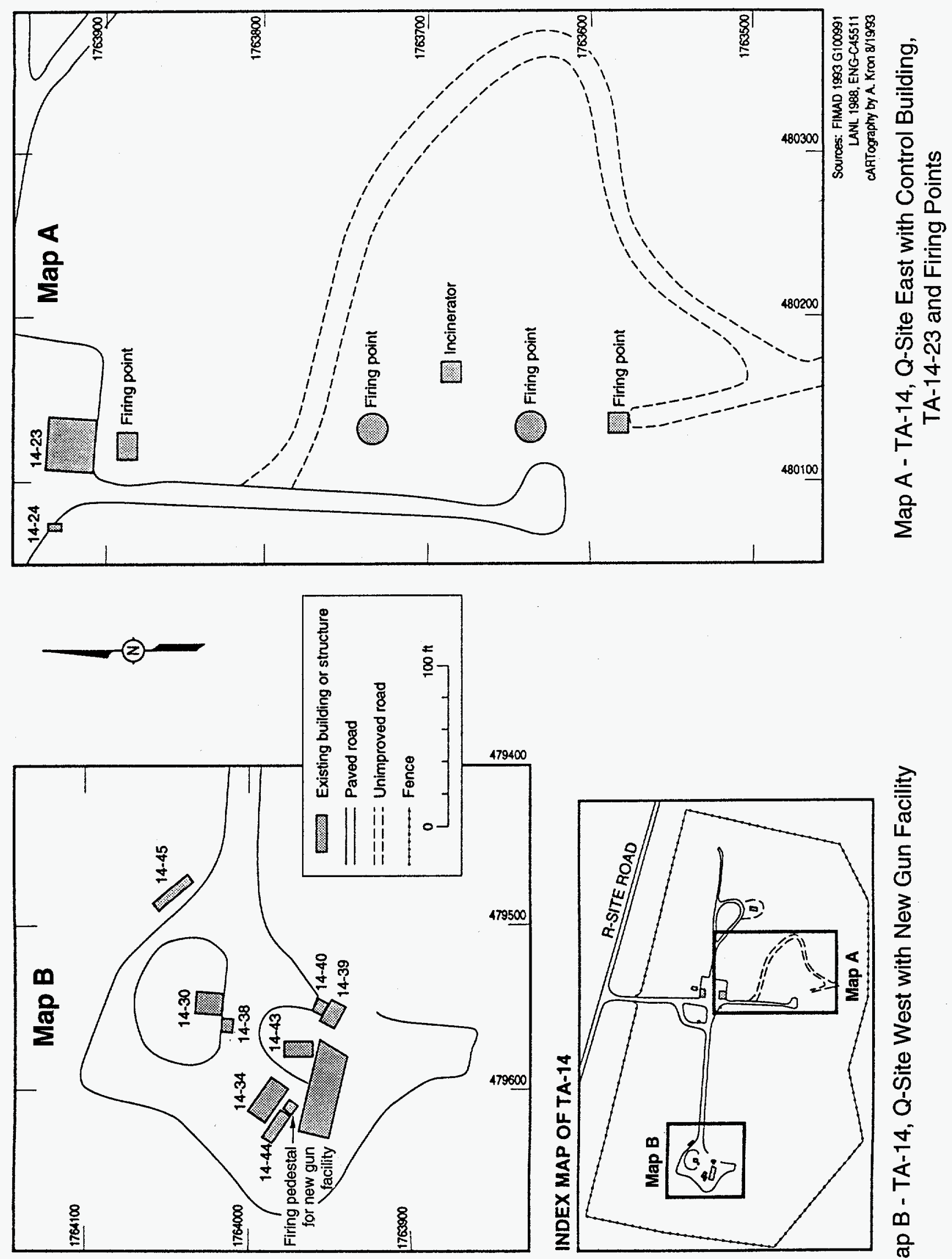

吾 

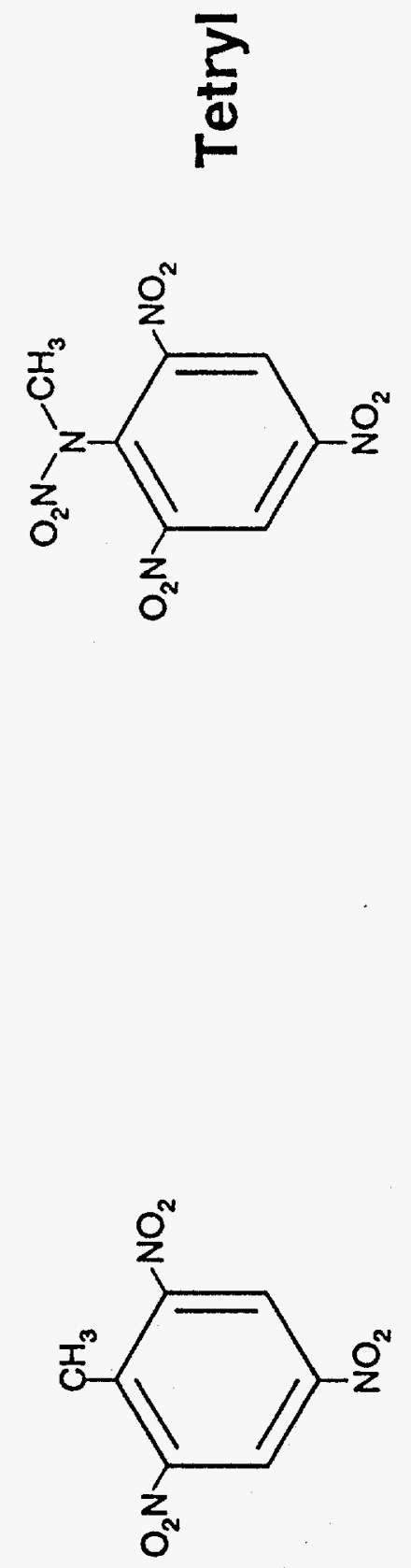

$$
\text { t }
$$
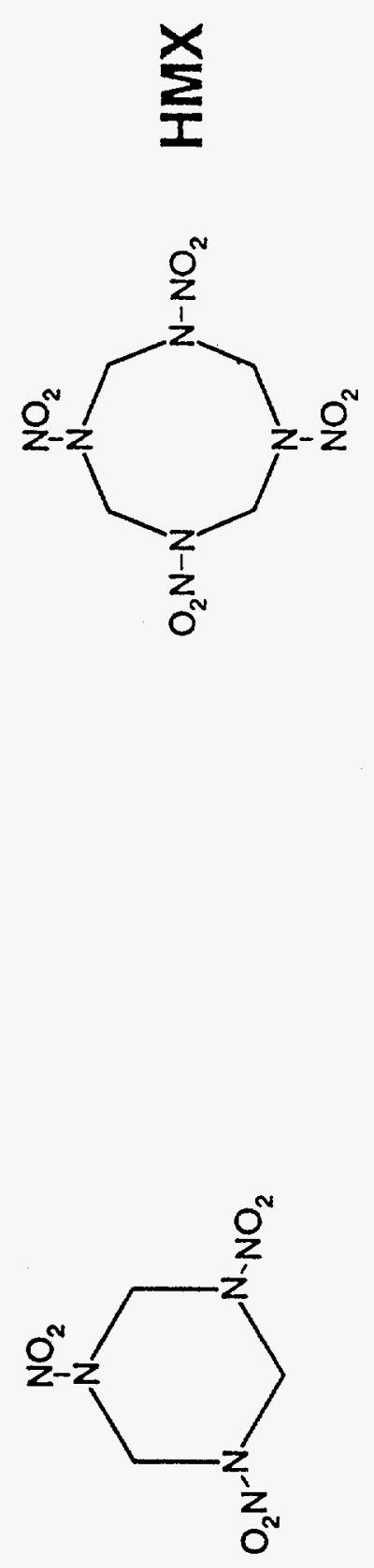

ํㅗㅁ $\underset{\underline{w}}{z}$
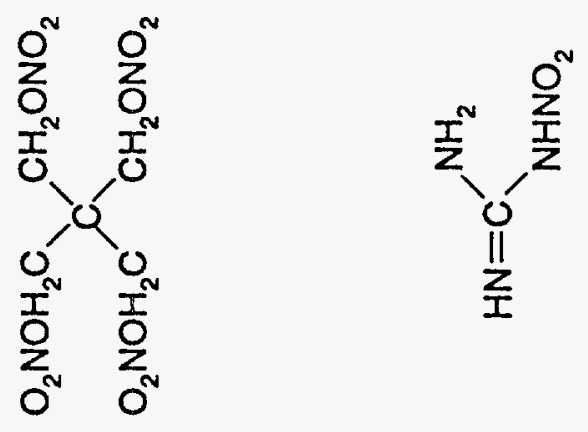

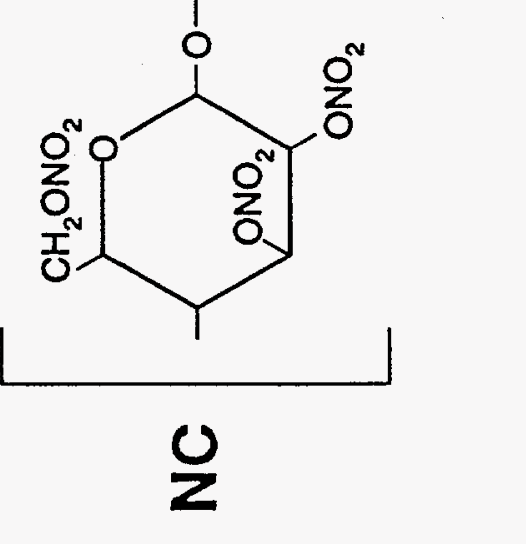

